\title{
Co-cultivation of the strictly anaerobic methanogen Methanosarcina barkeri with aerobic methanotrophs in an oxygen-limited membrane bioreactor
}

\author{
Michiel H. in 't Zandt ${ }^{1,2} \cdot$ Tijs J. M. van den Bosch $^{1} \cdot$ Ruud Rijkers $^{1} \cdot$ Maartje A. H. J. van Kessel ${ }^{1} \cdot$ Mike S. M. Jetten $^{1,2,3}$ • \\ Cornelia U. Welte ${ }^{1,3}$
}

Received: 26 February 2018 / Revised: 16 April 2018 / Accepted: 18 April 2018 / Published online: 3 May 2018

(C) The Author(s) 2018

\begin{abstract}
Wetlands contribute to $30 \%$ of global methane emissions due to an imbalance between microbial methane production and consumption. Methanogenesis and methanotrophy have mainly been studied separately, and little is known about their potential interactions in aquatic environments. To mimic the interaction between methane producers and oxidizers in the environment, we co-cultivated the methanogenic archaeon Methanosarcina barkeri with aerobic Methylocystaceae methanotrophs in an oxygenlimited bioreactor using acetate as methanogenic substrate. Methane, acetate, dissolved oxygen, available nitrogen, $\mathrm{pH}$, temperature, and cell density were monitored to follow system stability and activity. Stable reactor operation was achieved for two consecutive periods of 2 months. Fluorescence in situ hybridization micrographs indicated close association between both groups of microorganisms. This association suggests that the methanotrophs profit from direct access to the methane that is produced from acetate, while methanogens are protected by the concomitant oxygen consumption of the methanotrophs. This proof of principle study can be used to set up systems to study their responses to environmental changes.
\end{abstract}

Keywords Co-culture $\cdot$ Methane cycle $\cdot$ Aggregation $\cdot$ Methanogens $\cdot$ Methanotrophs

\section{Introduction}

Wetlands are the biggest natural methane source and contribute $30 \%$ to global methane emissions $\left(167 \mathrm{Tg} \mathrm{CH}_{4}\right.$ /year) (Saunois et al. 2016). Methane is an important greenhouse gas (GHG) with a 34-fold higher warming potential than $\mathrm{CO}_{2}$ (Myhre et al. 2013). Eighteen percent of the total global

Electronic supplementary material The online version of this article (https://doi.org/10.1007/s00253-018-9038-x) contains supplementary material, which is available to authorized users.

Cornelia U. Welte

c.welte@science.ru.nl

1 Department of Microbiology, Institute for Water and Wetland Research, Radboud University, Heyendaalseweg 135, 6525 AJ Nijmegen, The Netherlands

2 Netherlands Earth System Science Center, Utrecht University, Heidelberglaan 2, 3584 CS Utrecht, The Netherlands

3 Soehngen Institute of Anaerobic Microbiology, Radboud University, Heyendaalseweg 135, 6525 AJ Nijmegen, The Netherlands greenhouse effect is currently attributed to methane (Prather et al. 2012; Myhre et al. 2013). In wetlands, methanogenic archaea carry out the final reaction in the anaerobic degradation of organic matter resulting in methane production. Wetland methane emissions are mitigated by the activity of both anaerobic methanotrophic bacteria and archaea (Raghoebarsing et al. 2006; Ettwig et al. 2010; Haroon et al. 2013) and aerobic methanotrophic bacteria (reviewed by Hanson and Hanson 1996). Aerobic methanotrophy has been estimated to be the most significant methane oxidation pathway in cold ecosystems (Mackelprang et al. 2011; Barbier et al. 2012; Knoblauch et al. 2013), although anaerobic methane oxidizers have also been detected in cold freshwater and peatland ecosystems (Smemo and Yavitt 2011; Gupta et al. 2013; Kao-Kniffin et al. 2015). Early studies on lake and peatland systems indicated that aerobic methanotrophs have the potential to oxidize up to $95 \%$ of the methane that is produced (Yavitt et al. 1988; Frenzel et al. 1990). Spatial coexistence has been observed in, for example, cooperation of nitrogen cycle microorganisms (Sliekers et al. 2002; Yang et al. 2012). Several studies implied that this coexistence in 
seemingly anoxic environments is probably enabled due to high oxygen consumption rates (Oswald et al. 2016; Martinez-Cruz et al. 2017). In addition, aerobic methanotrophs are tolerant to long periods of anoxic conditions (Roslev and King 1994).

The interactions between methanogens and aerobic methanotrophs that may strongly control the GHG fluxes of cold wetland ecosystems remain poorly understood (Bridgham et al. 2013). Only few studies on methane fluxes in oxic-anoxic systems have been done so far (Gerritse and Gottschal 1993; Shen et al. 1996; Miguez et al. 1999). Shen et al. designed a bioreactor with an aerobic-anaerobic interface using a granular sludge bed that allowed for sufficient methanogenic activity to support growth of the aerobic methanotroph Methylosinus sporium (Shen et al. 1996). However, this system did not employ axenic cultures and observations showed gradual reduction of M. sporium, indicating competition for oxygen with facultative anaerobic bacteria. Similarly, Miguez et al. used an upflow anaerobic sludge blanket (UASB) reactor to co-cultivate complex methanogenic cultures with the aerobic methanotrophs Methylosinus trichosporium and M. sporium (Miguez et al. 1999). Gerritse and Gottschal were the first to set up defined co-cultures with Methanosarcina barkeri and Methanobacterium formicicum together with aerobic methanotrophic Methylocystis sp. (Gerritse and Gottschal 1993). However, in-depth data on species interactions are lacking. Here, we established a co-culture of the methanogen M. barkeri and aerobic Methylocystaceae methanotrophs in a membrane bioreactor to generate a method to study interspecies interactions between methane cycle microorganisms. Under oxygen-limited conditions, a stable co-culture was monitored over time and several key parameters were determined.

\section{Materials and methods}

\section{Strains}

M. barkeri DSM 800 and Methylosinus sporium DSM 17706 strains were ordered from the DSMZ (Leibniz Institute DSMZ-German Collection of Microorganisms and Cell Cultures, Braunschweig, Germany) as actively growing cultures. M. sporium was chosen for high substrate affinity (Murrell et al. 2000) and co-occurrence in methanogenic-methanotrophic cultures (Shen et al. 1996; Miguez et al. 1999). Genomic analysis of the M. sporium culture indicated presence of a second strain of another Methylocystaceae species related to Methylocystis rosea, as described in detail in the "Results" section. M. barkeri was chosen for the oxygen-limited reactor set-up due to its relative high oxygen tolerance (up to several hours under atmospheric oxygen levels) and wide substrate range (Kiener and Leisinger 1983; Brioukhanov et al. 2000; Maeder et al. 2006). Furthermore, its reference genome is available (PRJNA230939). M. barkeri can perform acetoclastic methanogenesis via acetate dismutation to methane and $\mathrm{CO}_{2}$. In addition, M. barkeri can be grown on mineral media, a prerequisite for this cocultivation study (Maestrojuan and Boone 1991). M. sporium was pre-grown on general medium as described at "Reactor set-up and co-cultivation." $M$. barkeri was pre-grown on methanogen medium (1.7 mM KH $\mathrm{KHO}_{4}, 0.9 \mathrm{mM} \mathrm{NH}{ }_{4} \mathrm{Cl}, 0.2 \mathrm{mM} \mathrm{MgSO}{ }_{4}$. $7 \mathrm{H}_{2} \mathrm{O}, 0.2 \mathrm{mM} \mathrm{CaCl}{ }_{2} \cdot 2 \mathrm{H}_{2} \mathrm{O}, 0.5 \mathrm{mM} \mathrm{NaCl}, 0.7 \mu \mathrm{M}$ $\mathrm{FeSO}_{4} \cdot 7 \mathrm{H}_{2} \mathrm{O}, 0.25 \mathrm{~g} / \mathrm{L}$ Tryptone, $0.25 \mathrm{~g} / \mathrm{L}$ yeast extract, $1 \mathrm{~mL} 1000 \times$ trace elements SL-6 including $81.5 \mu \mathrm{M}$ $\mathrm{CeCl} \cdot 7 \mathrm{H}_{2} \mathrm{O}$ (DSMZ, Braunschweig, Germany), and $1 \mathrm{~mL} 1000 \times$ vitamin solution (DSMZ, Braunschweig, Germany) with $100 \mathrm{mM}$ acetate and using $0.001 \%$ resazurin $(w / v)$ as redox indicator). $\mathrm{pH}$ was adjusted to 8.5 with sodium hydroxide, and bottles were made anoxic with a triplicate +1 bar overpressure gas followed by a 15 min vacuum cycle using a 9:1 Argon/ $/ \mathrm{CO}_{2}$ gas mixture resulting in a $\mathrm{pH}$ of around 7.0 after autoclaving.

\section{Reactor set-up and co-cultivation}

Reactor set-up A 2 L membrane bioreactor (MBR, see Yoon (2016) for details) with an operational volume of $1.5 \mathrm{~L}$, and a settling and bleed cycle to control growth rate, and to select for aggregates, was designed for the co-culturing of methanogens and aerobic methanotrophs (Fig. 1). A general medium was devised that allowed growth of both methanogens and methanotrophs $\left(1.0 \mathrm{mM} \mathrm{MgSO}_{4} \cdot 7 \mathrm{H}_{2} \mathrm{O}\right.$, $0.23 \mathrm{mM} \mathrm{CaCl} \cdot 2 \mathrm{H}_{2} \mathrm{O}, 1.7 \mathrm{mM} \mathrm{KH} \mathrm{PO}_{4}, 5.1 \mathrm{mM} \mathrm{NaCl}$, $7.2 \mu \mathrm{M} \mathrm{FeSO} 4 \cdot 7 \mathrm{H}_{2} \mathrm{O}, 3.7 \mathrm{mM} \mathrm{NH} \mathrm{N}_{4} \mathrm{Cl}, 26.2 \mathrm{mM}$ $\mathrm{CH}_{3} \mathrm{COOH}, 0.25 \mathrm{~g} / \mathrm{L}$ Tryptone, $0.25 \mathrm{~g} / \mathrm{L}$ yeast extract, $1 \mathrm{~mL} 1000 \times$ trace elements SL-6 including $81.5 \mu \mathrm{M}$ $\mathrm{CeCl} \cdot 7 \mathrm{H}_{2} \mathrm{O}$ (DSMZ, Braunschweig, Germany), and $1 \mathrm{~mL}$ $1000 \times$ vitamin solution (DSMZ, Braunschweig, Germany)). $\mathrm{pH}$ was adjusted to 7.0. At $t=111$ days, Tryptone and yeast extract were removed from the medium to reduce risk of contamination in the bioreactor. Growth tests on Tryptone and yeast extract free medium confirmed that growth of both methanogens and methanotrophs was possible (data not shown). The total medium flow supply was set to $0.5 \mathrm{~L} /$ day, and the volume was kept constant at $1.5 \mathrm{~L}$ using a level-controlled effluent pump. The gas flow rate was set to $5 \mathrm{~mL} / \mathrm{min}$. Initial gas mixture composition was set to $1.51 \mathrm{~mL}$ Argon/ $/ \mathrm{CO}_{2}(9: 1)$ mixture, $2.38 \mathrm{~mL}$ air, and $0.75 \mathrm{~mL}$ methane. After 15 weeks of co-cultivation, the gas inflow was increased to $10 \mathrm{~mL} / \mathrm{min}$ to reduce the risk of air diffusion into the reactor. Simultaneously, the methane inflow percentage was reduced based on the prevailing methane consumption data. The mixture 


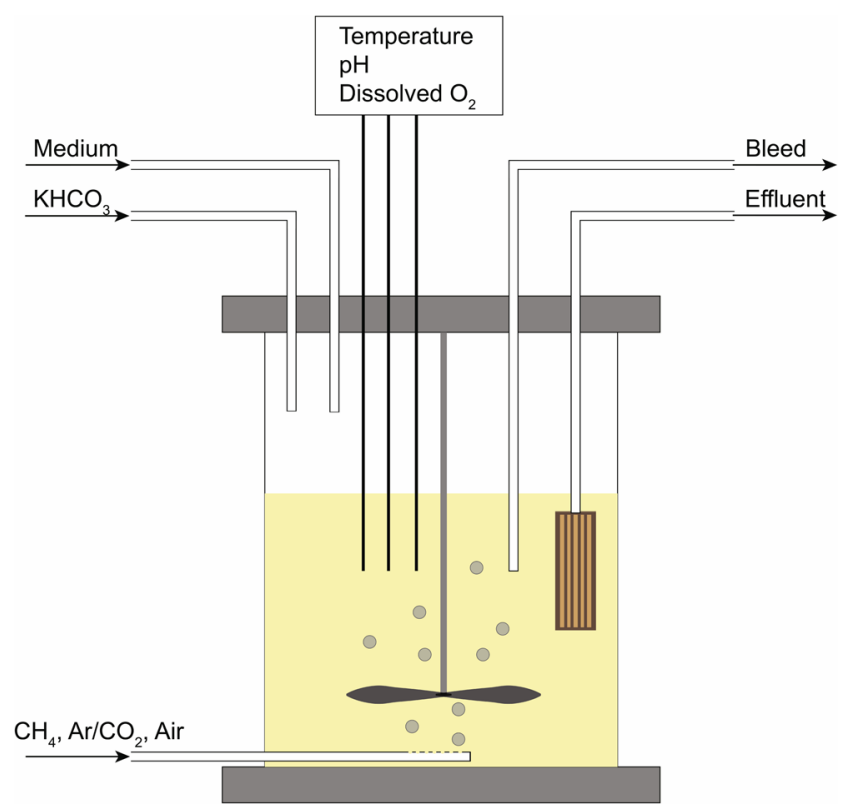

Fig. 1 Set-up of the $2 \mathrm{~L}$ membrane bioreactor (MBR) with a constant volume of $1.5 \mathrm{~L}$. The inflow gas was a mixture of $\mathrm{CH}_{4}$, Argon and $\mathrm{CO}_{2}$, and compressed air of which the ratios could be modified. Medium and buffer $\left(\mathrm{KHCO}_{3}\right)$ inflows and bleed and effluent outflows were controlled by calibrated medium pumps. Temperature, $\mathrm{pH}$ and dissolved $\mathrm{O}_{2}$ were constantly monitored using in-liquid probes. Contents were mixed at $150 \mathrm{rpm}$ with a stainless steel rotor blade

contained $6.77 \mathrm{~mL}$ argon/ $/ \mathrm{CO}_{2}, 2.86 \mathrm{~mL}$ air, and $0.37 \mathrm{~mL}$ methane per minute. $\mathrm{O}_{2}$ and $\mathrm{pH}$ were monitored using AppliSens probes (AppliSens Z001023551 and Applisens Z010023520, Applikon Biotechnology B.V., Delft, The Netherlands). The $\mathrm{pH}$ was controlled at $7.0 \pm 0.1 \mathrm{using}$ a probe-linked $\mathrm{KHCO}_{3}$ pump. The MBR was continuously mixed at $150 \mathrm{rpm}$ using a stainless steel rotor blade controlled by an Applikon stirrer controller (Applikon stirrer controller P100, Applikon Biotechnology B.V., Delft, The Netherlands). The system was operated at room temperature $\left( \pm 20^{\circ} \mathrm{C}\right)$.

Co-cultivation The methanotroph-only culture was grown to OD600 of 0.7 under oxygen limitation, which created anoxic conditions in the liquid. After at least a week of anoxia $\left(\mathrm{O}_{2}\right.$ detection limit $\left.3 \mu \mathrm{M}\right)$, the reactor was inoculated with $M$. barkeri. Fourteen days after inoculation with M. barkeri, a bleed cycle was introduced to select for methanogen-methanotroph aggregates and to remove excess methanotrophic biomass. The bleed cycle was set to 30 min pre-settling (no stirring) to minimize loss of aggregates followed by removal of $50-\mathrm{mL}$ reactor fluid from the upper layer in $20 \mathrm{~min}$. Triplicate samples were taken every 3-4 days. Cells and supernatant were taken aseptically from the MBR and separated by centrifugation for $10 \mathrm{~min}$ at maximum speed $(20,348 \times g)$ and used for protein determination, FISH microscopy, and activity tests.
Monitoring of growth and substrate metabolism

OD600 and protein assay After sterilization, the bioreactor was inoculated with $M$. sporium. Batch culture and reactor optical density were measured on a Bio-Rad SmartSpec ${ }^{\mathrm{TM}}$ 3000 spectrophotometer with the pre-set OD600 method (Bio-Rad Laboratories, Veenendaal, The Netherlands) using 1.6-mL semi-micro polystyrene cuvettes (Sarstedt AG \& Co. KG, Nümbrecht, Germany). For analysis of total protein contents, duplicate $1.5 \mathrm{~mL}$ reactor liquid pellets were resuspended in $0.3 \mathrm{~mL} 3 \mathrm{M} \mathrm{NaOH}$ and boiled for $10 \mathrm{~min}$ at $95^{\circ} \mathrm{C}$. Samples were cooled down to RT, neutralized with $0.3 \mathrm{~mL} 3 \mathrm{M} \mathrm{HCl}$, and centrifuged for $1 \mathrm{~min}$ at maximum speed. Ten microliters supernatant was loaded onto a polystyrene flat-based 96-well microtest plate (Sarstedt AG \& Co. KG, Nümbrecht, Germany). To each well, $200 \mu \mathrm{l}$ working solution (50 parts of Pierce BCA Protein Assay Kit, reagent A (article no 23223) and 1 part of $4 \%$ cupric sulfate in Milli-Q water was added and mixed by pipetting. Samples were incubated for $30 \mathrm{~min}$ at $60{ }^{\circ} \mathrm{C}$. After cooling down to room temperature, the absorbance was measured at $562 \mathrm{~nm}$ on a SpectraMax 190 Microplate Reader (Molecular Devices, Sunnyvale CA, USA), and data were analyzed using SoftMax Pro 6.4 (Molecular Devices, Sunnyvale CA, USA). Values were compared to a standard curve with bovine serum albumin (BSA) in Milli-Q. OD600 values and total protein analysis achieved similar results (Supplementary Information Fig. S1).

Methane and oxygen For all gas determinations, $50 \mu \mathrm{l}$ gas samples were withdrawn with a gas-tight glass syringe (Hamilton, Reno NE, USA). Methane in- and outflow concentrations were measured daily using a HP5890a gas chromatograph (Hewlett Packard 5890a, Agilent Technologies, Santa Clara CA, US) equipped with a Porapaq Q 100/120 mesh and a thermal conductivity detector (TCD) using $\mathrm{N}_{2}$ as carrier gas (Sigma-Aldrich, Saint Louis MI, USA). Data were analyzed using GC ChemStation Rev. A.10.02 (Agilent Technologies, Santa Clara CA, USA). Oxygen concentrations were determined with the same gas sampling and volume on an Agilent 6890 series gas chromatograph coupled to a mass spectrometer (Agilent Technologies, Santa Clara CA, USA) equipped with a Porapaq Q column heated at $80{ }^{\circ} \mathrm{C}$ with helium as carrier gas. Data were analyzed with the MSD ChemStation F01.01.2317 (Agilent Technologies, Santa Clara, CA, USA). All gas measurements were performed in duplicate.

Acetate Acetate concentrations were determined according to the protocol described by Kage and co-workers with the following modifications: An internal standard (IS) was prepared by dissolving $0.1 \mathrm{mM}$ methylstearate (MS) 
in n-hexane (Kage et al. 2004). For each reaction, $40 \mu \mathrm{l}$ supernatant sample, $40 \mu 10.5 \mathrm{M}$ phosphate-buffered saline (PBS $65 \mathrm{mM} \mathrm{NaCl}, 5 \mathrm{mM}$ phosphate buffer $\mathrm{pH} 7.4$ $\left(80 \% \mathrm{Na}_{2} \mathrm{HPO}_{4}\right.$ and $\left.20 \% \mathrm{NaH}_{2} \mathrm{PO}_{4}\right)$ ), and $200 \mu \mathrm{l}$ pentafluorobenzyl bromide (PFBBr) in acetone at a concentration of $100 \mathrm{mM}$ were mixed and incubated for $1 \mathrm{~h}$ at $60{ }^{\circ} \mathrm{C}$. Acetate standard solutions were prepared according to Kage et al. (2004) using sodium acetate in Milli-Q water with a concentration range from 0 to $10 \mathrm{mM}$. Four hundred microliters of the $0.1 \mathrm{mM}$ MS solution in $\mathrm{n}$-hexane was added, and samples were vortexed for $1 \mathrm{~min}$ at $\mathrm{RT}$ and centrifuged for $2 \mathrm{~min}$ at maximum speed. One hundred microliters aliquots were divided into $12 \times 32 \mathrm{~mm}$ clear Cronus crimp vials capped with rubber/PTFE snap caps (SMI-LabHut Ltd., Maisemore, UK); $0.1 \mathrm{~mL} 15 \mathrm{~mm}$ tip clear glass inserts were used to reduce the required sample volume (VWR International BV, Amsterdam, The Netherlands). Pure nhexane was added to the vials to avoid excess sample evaporation. All samples were injected five times on a JEOL AccuTOF-GCv JMS-100GCv (JEOL Ltd., Akishima, Tokyo, Japan).

Ammonium and nitrite Ammonium concentrations were measured using $50 \mu \mathrm{l}$ supernatant sample and $750 \mu \mathrm{l}$ OPA Reagent $(0.54 \%(w / v)$ ortho-phthaldialdehyde, $0.05 \%(v / v) \beta$-mercaptanol and $10 \%(v / v)$ ethanol in $400 \mathrm{mM}$ potassium phosphate buffer ( $\mathrm{pH}$ 7.3)). Samples were vortexed shortly and incubated at room temperature (RT) for $20 \mathrm{~min}$. Absorbance was measured at $420 \mathrm{~nm}$ and values were compared to a calibration curve with ammonium chloride in Milli-Q. Nitrite concentrations were measured using $100 \mu \mathrm{l}$ sample, $100 \mu \mathrm{l}$ nitrite reagent $(1 \%(w / v)$ sulfanilic acid in $1 \mathrm{M} \mathrm{HCl}$ and $100 \mu \mathrm{l} 0.1 \%(w /$ $v$ ) naphtylethylene diaminedihydrochloride in water). Samples were mixed by pipetting and incubated for $20 \mathrm{~min}$ at RT. Standard curves were prepared by using a dilution series of sodium nitrite in Milli-Q. Absorbance was measured at $540 \mathrm{~nm}$. Both assays were performed in triplicate in a 96-well plate set-up as described for the protein assay.

\section{Fluorescence in situ hybridization (FISH) microscopy}

FISH microscopy samples were taken weekly and prepared in duplicate according to the FISH protocol as described by Amann et al. (1990) using a hybridization buffer with $35 \%(v / v)$ formamide. M. sporium was targeted using bacterial EUB mix probes (5'-GCT GCC TCC CGT AGG AGT-3'; 5'-GCA GCC ACC CGT AGG TGT-3'; 5'-GCA GCC TTC CGT AGA AGT-3') (Daims et al. 1999). M. barkeri was targeted by a combination of ARCH-0890 probe (5'-GTG CTC CCC CGC CAA TTC
CT-3') targeting archaea (Stahl and Amann 1991) and MSMX-0860 probe (5'-GGC TCG CTT CAC CGC TTC CCT-3') targeting Methanosarcinaceaea (Raskin et al. 1994).

\section{Genome sequencing and data analysis of methanotrophic culture}

DNA was extracted from $20 \mathrm{~mL}$ pelleted methanotrophic culture grown to an OD600 of $\sim 1$. DNA was extracted using the cetyltrimethylammoniumbromide (CTAB) extraction buffer protocol as described by Zhou et al. (1996). DNA library preparation and sequencing was performed by BaseClear on an Illumina HiSeq2500 platform using the Illumina paired end protocol (BaseClear B.V., Leiden, The Netherlands). Qualitytrimming, adapter removal, and contaminant-filtering of Illumina HiSeq paired-end sequencing reads was performed using BBDUK (BBTOOLS version 37.76) (Bushnell 2014). Trimmed reads were assembled using metaSPAdes v3.11.1 (Nurk et al. 2017) at default settings. MetaSPAdes iteratively assembled the metagenome using k-mer size 21, 33, 55, 77, 99, and 127. Reads were mapped back to the metagenome using Burrows-Wheeler Aligner 0.7.17 (BWA) (Li and Durbin 2018), employing the "mem" algorithm. The sequence mapping files were handled and converted as needed using SAMtools 1.6 ( $\mathrm{Li}$ et al. 2018). Metagenome binning was performed for contigs greater than $1500 \mathrm{bp}$ using five binning algorithms: BinSanity v0.2.6.1 (Graham et al. 2017), COCACOLA (Lu et al. 2018), CONCOCT (Alneberg et al. 2014), MaxBin 2.0 2.2.4 (Wu et al. 2015), and MetaBAT 2 2.12.1 (Kang et al. 2015). The bin sets from each algorithm were supplied to DAS Tool 1.0 (Sieber et al. 2017) for consensus binning to obtain the final optimized bins. The quality of the generated bins was assessed through single-copy marker gene analysis using CheckM 1.0.7 (Parks et al. 2015). Genomes were annotated with Prokka 1.12 (Seemann 2014) using the NCBI Reference Sequence Database (RefSeq) release 85 (Pruitt et al. 2018). Predicted protein sequences were submitted to the KEGG Automatic Annotation Server (KAAS - last update April 3, 2015) (Moriya et al. 2007) for pathway analyses. Genome annotations were examined using the Artemis genome browser release 16.0.0 (Rutherford et al. 2000). For $16 \mathrm{~S}$ rRNA gene analysis, raw Illumina HiSeq reads were mapped against the SILVA SSU non-redundant database version 128 and de novo assembled as described in in 't Zandt et al. (2017).

\section{Nucleotide sequence accession numbers}

All sequencing data were submitted to the GenBank databases under BioProject PRJNA434352. The genome bins were submitted as genome data under BioSample accession number SAMN08554708 and SAMN08554709. 


\section{Results}

\section{Start-up of the oxygen-limited bioreactor}

A membrane bioreactor was inoculated with aerobic methanotrophs and fed with a gas mixture containing methane and oxygen. A stable co-culture of anaerobic methanogens and aerobic methanotrophs could be obtained for over 2 months. Optical density (OD) was followed over time (Fig. 2). The initial phase with only aerobic methanotrophs indicated a rapid growth based on an OD600 increase from 0.3 to 0.85 within 55 days. The methanotrophs were put under oxygen limitation, and after the dissolved oxygen levels dropped below the detection limit $(\leq 3 \mu \mathrm{M})$, the OD600 was diluted to 0.5 and the reactor was inoculated on $t=92$ days with the methanogenic archaeon $M$. barkeri. Oxygen levels remained below the detection limit for the entire experiment. At $t=$ 105 days, methane inflow was reduced to $1.25 \mathrm{~mL} / \mathrm{min}$ to restrict methanotrophic growth. Co-culture OD values increased to almost 1 within 19 days. At $t=113$ days, additional biomass was removed and a bleed was installed to remove $1 / 30$ th of the reactor volume per day to target an OD600 of around 0.5. From $t=113$ days to the end of reactor operation at $t=337$ days OD600 values ranged from 0.4 to 0.7 .

\section{Reducing methane flux results in higher reactor stability}

Inflow and outflow methane concentrations were measured to follow methanotrophic activity (Fig. 3). During precultivation with methanotrophs ( $t=0$ to 92 days), methane consumption was highly variable as indicated by the deviation in the data. Directly after the inoculation with M. barkeri at $\mathrm{t}=92$ days, the total methane consumption rates increased about tenfold from days 92 to 104 with an average of $41.4 \pm 0.8$ (standard error, SE) $\mathrm{mmol} / \mathrm{day}$, probably due to removal of excess (inactive) biomass prior to inoculation. A similar observation was made between $t=$ 55 and 65 days after excess biomass was removed. Methane consumption rates increased to an average of $43.5 \pm 1.4(\mathrm{SE}) \mathrm{mmol} / \mathrm{day}$. On $t=205$ days, methane influx was lowered to $0.62 \mathrm{~mL} / \mathrm{min}$ to reduce methanotrophic growth and to make the system more dependent on internally produced methane. After second addition of $M$. barkeri on $t=252$ days, this resulted in the observation of up to ten times more methanogen-methanotroph aggregates.

Ammonium and nitrite concentrations were measured weekly within the co-cultivation periods from $t=83$ to $t=$ 315 days to monitor nitrogen availability, consumption, and nitrite toxicity risk (data not shown). Total available ammonium ranged between 2.3 and $4.7 \mathrm{mM}$ with an average of $3.3 \pm$ 0.5 (standard deviation, SD) $\mathrm{mM}$.

\section{Monitoring showed constant availability and consumption of acetate}

Five millimolars of acetate was added to the medium as methanogenic substrate. Acetate concentrations were monitored weekly (Fig. 4). These data indicated acetate consumption during the pre-cultivation period and thus suggested that the methanotrophic bacteria assimilated some of the acetate into biomass. M. barkeri Ks for acetate is $3-5 \mathrm{mM}$, and the threshold is $0.2-1.2 \mathrm{mM}$ (Daniels 1993). Acetate concentrations were increased to $10 \mathrm{mM}$ after 92 days to reduce acetate limitation risks for the methanogens. Further measurements indicated that acetate was not limiting during the entire cocultivation periods.
Fig. 2 Optical density of biomass during operation of the membrane bioreactor. Gray areas indicate cocultivation periods. At $t=92$, methanogens were added. The first co-cultivation lasted until $t=$ 155 days. At $t=252$, a second batch of $M$. barkeri was added. The second co-cultivation lasted until $t=317$. The dashed line indicates installation of the bleed at $t=113$

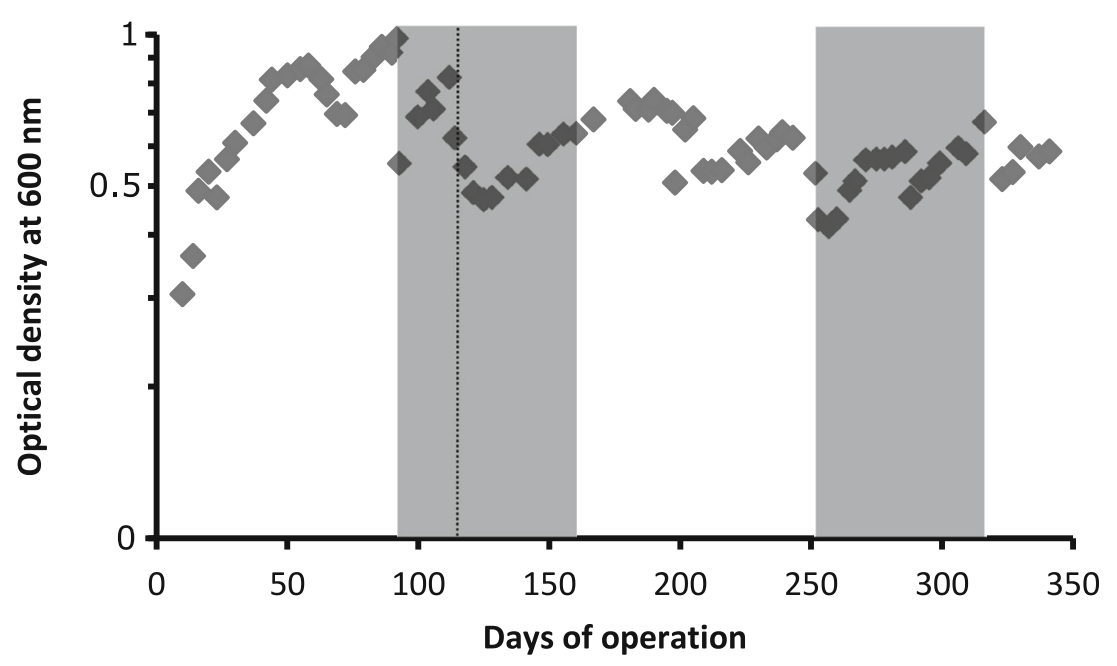


Fig. 3 Total methane consumption in $\mathrm{mmol} /$ day as measured by reactor inflow and outflow gas methane concentrations. Gray areas indicate cocultivation periods. At $t=92$, methanogens were added. The first co-cultivation lasted until $t=$ 155 days. At $t=252$, a second batch of $M$. barkeri was added. The second co-cultivation lasted until $t=317$. Right top graph shows zoom-in from $t=200$ to $t=350$ days

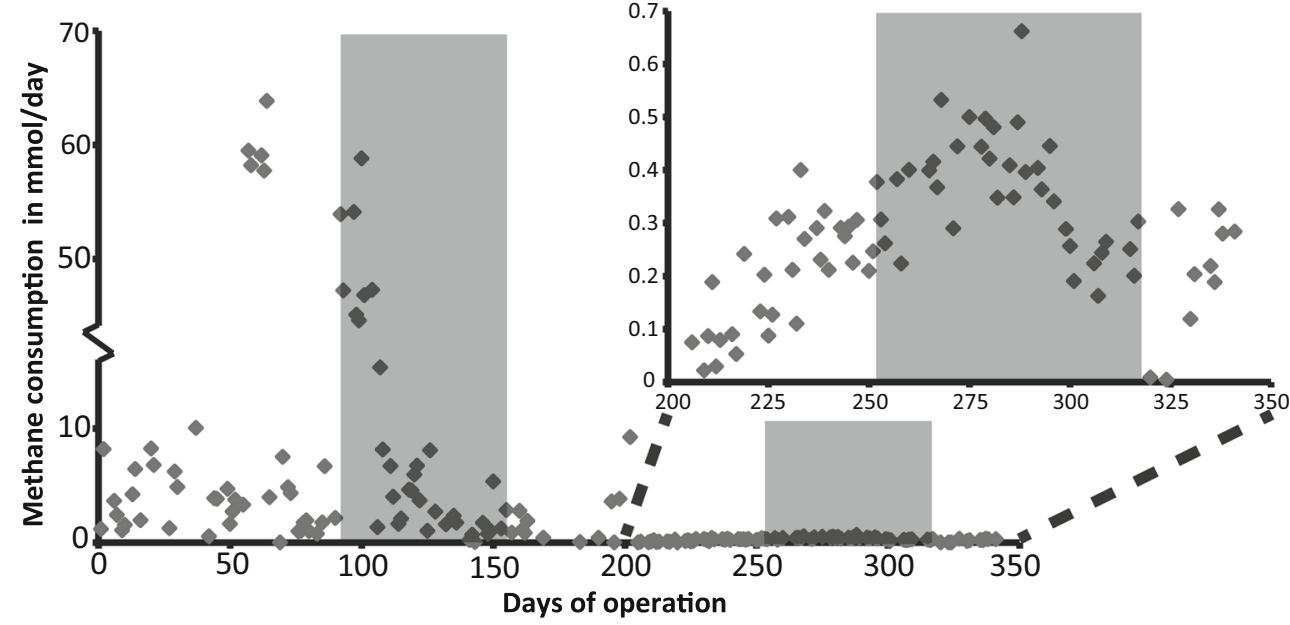

\section{Fluorescence in situ hybridization showed clustering of methanogens and aerobic methanotrophs}

Using fluorescence in situ hybridization (FISH) microscopy, the formation of aggregates containing both aerobic methanotrophs and anaerobic methanogens was detected over time (Fig. 5a-d). Abundance estimations from the FISH micrographs indicated a ratio of methanotrophs to methanogens of around 100:1, which was supported by the observed rapid growth of the methanotrophic population. First distinct aggregates were observed after 22 days of co-cultivation (Fig. 5b). The structure of the aggregates after $49(t=142)$ and $63(t=156)$ days of co-cultivation (Fig. 5c, d) showed a center or multiple centers of methanogen clusters (sarcina-shaped cell packages) surrounded by multiple cell layers of methanotrophs. This led to the hypothesis that both methanogens and aerobic methanotrophs profit from this specific spatial organization (Supplementary Information Fig. S2). Methanogenic capacity of the reactor contents was still retained when samples were batch cultured anaerobically with acetate as sole carbon source (data not shown).

\section{Lower methane/ammonium ratio induced nitrite toxicity event}

After reducing the methane influx to $0.62 \mathrm{~mL} / \mathrm{min}$ on $t=$ 205 days, nitrite increased from background levels of $15.6 \pm$ 10.8 (SD) $\mu \mathrm{M}$ to $78.6 \pm 4.8$ (SD), probably due to the nonspecific co-metabolism of ammonia by methane monooxygenase (MMO) of the aerobic methanotrophs under methane-limiting conditions. The nitrite accumulation resulted in a decrease of $M$. barkeri cells as could be observed by FISH microscopy (data not shown). To minimize the risk of ammonium co-metabolism, ammonium concentration in the inflow medium was lowered from 3.7 to $1 \mathrm{mM}$. Growth experiments with axenic cultures of $M$. barkeri indicated that growth was not limited by ammonium concentrations down to $1 \mathrm{mM}$ but was reduced when concentrations fell below $0.5 \mathrm{mM}$. Although the ammonium source is shared during
Fig. 4 Weekly measurements of the acetate concentrations in the reactor liquid. Gray areas indicate co-cultivation periods. At $t=92$, methanogens were added. The first co-cultivation lasted until $t=$ 155 days. At $t=252$, a second batch of $M$. barkeri was added. The second co-cultivation lasted until $t=317$. Error bars indicate standard error of the mean, $n=5$ technical replicate measurements on a JEOL AccuTOF-GCv

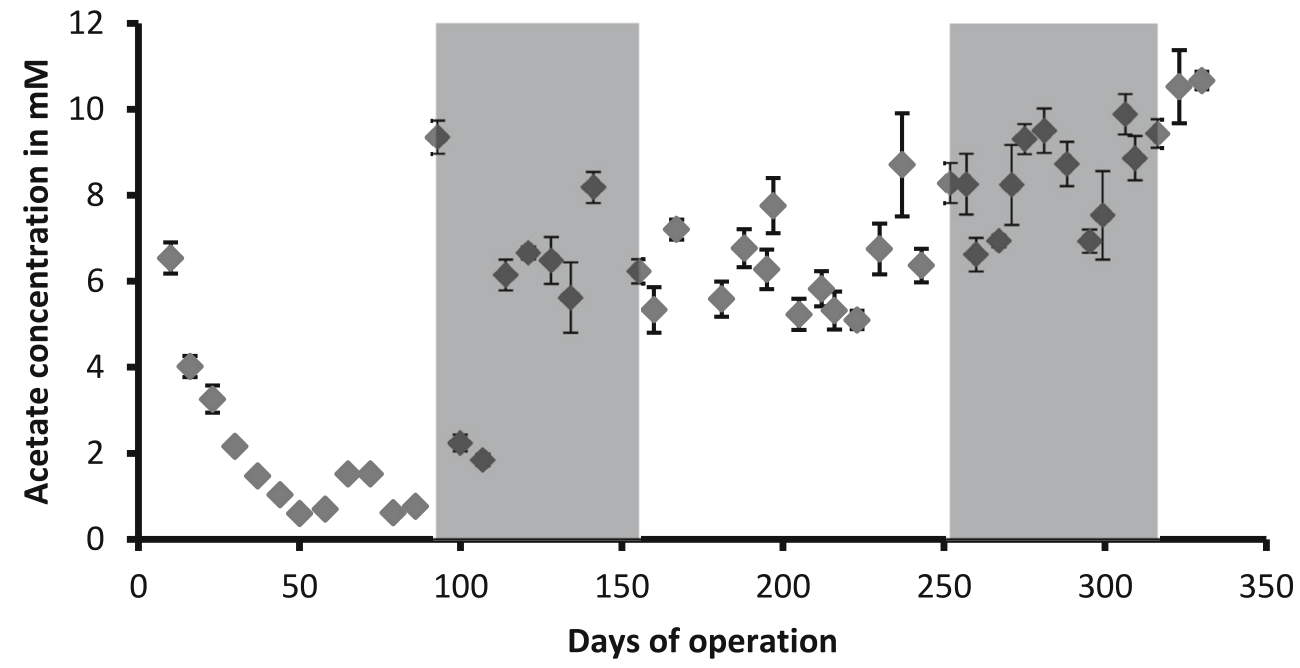



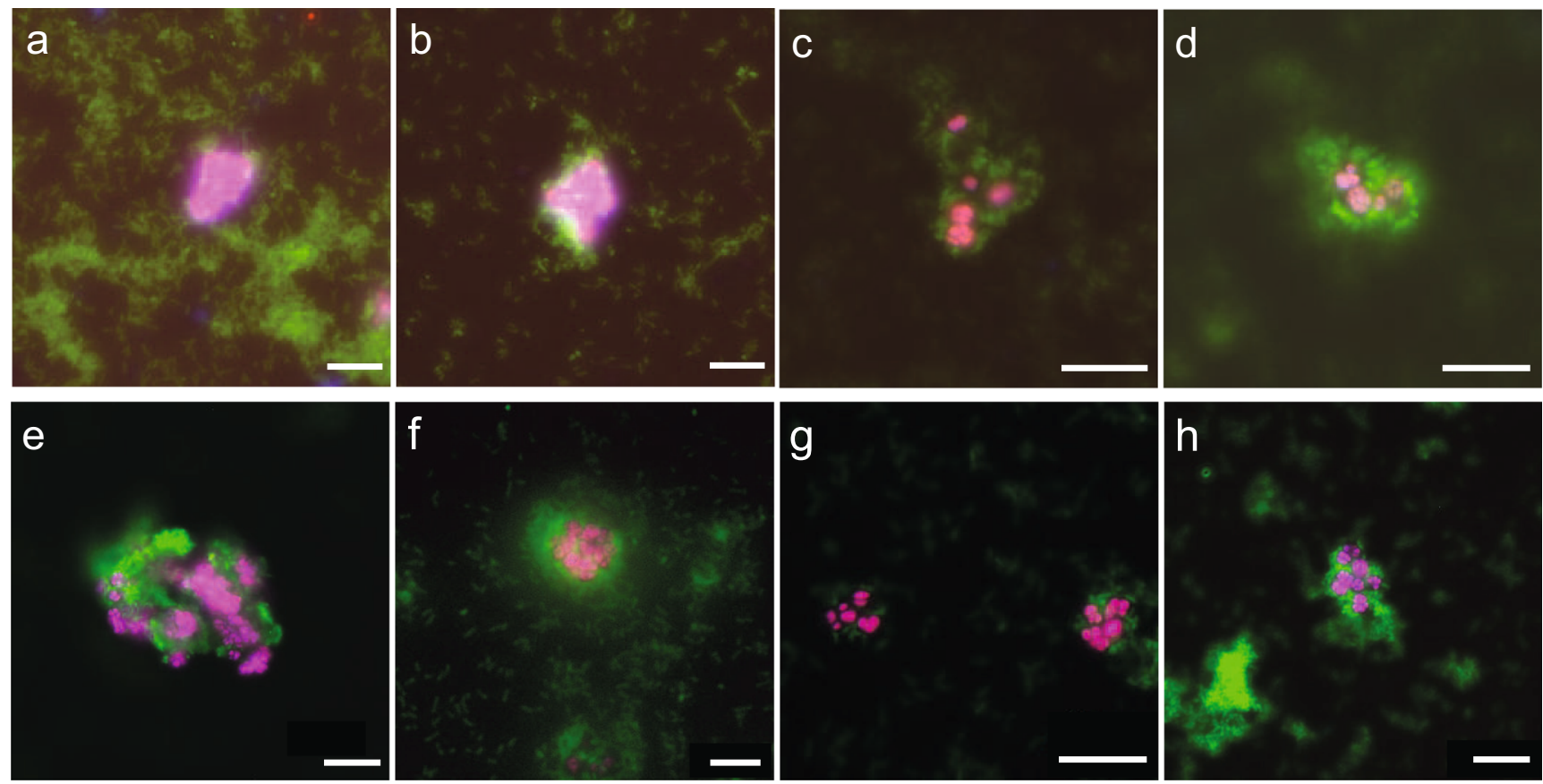

Fig. 5 a-d Fluorescence in situ hybridization micrographs of the reactor biomass after 1 (a), 22 (b), 49 (c), and 63 days (d) of inoculation with M. barkeri. $\mathbf{e}-\mathbf{h}$ Fluorescence in situ hybridization micrographs of the reactor biomass after $3(\mathbf{e}), 16(\mathbf{f}), 30(\mathbf{g})$, and 65 days $(\mathbf{h})$ of the second

inoculation with $M$. barkeri. Aerobic methanotrophic bacteria are stained in green (EUB mix), and M. barkeri are stained in magenta (overlay of ARCH-0890 and MSMX-0860 in blue and red respectively). Scale bars represent $10 \mu \mathrm{m}$

co-cultivation, reactor liquid ammonium concentrations never dropped below $0.5 \mathrm{mM}$ (data not shown). After system stabilization, a second inoculation with M. barkeri was performed ( $t=252$ days) to confirm the successful co-cultivation and to show repeated formation of interactions between methanogens and aerobic methanotrophs (Fig. 5e-h).

\section{Genome sequencing and analysis of aerobic methanotrophs}

To confirm the identity of the methanotrophs, the culture was sequenced using Illumina HiSeq technology. Sequence analysis was performed using consensus binning, annotation, and de novo assembly based on a $16 \mathrm{~S}$ rRNA gene identification approach. The culture appeared to contain two methanotrophic species. The first bin was assigned to Methylosinus (3.79 Mbp, GC-content 65.2\%, $\mathrm{N} 50=96,528 \mathrm{bp}, 55$ contigs $)$ and had $100 \%$ completeness, $0.31 \%$ contamination, and no strain heterogeneity. The second bin was identified as Methylocystis (4.36 Mbp, GC-content $62.5 \%, \mathrm{~N} 50=136,571 \mathrm{bp}, 55$ contigs) with $99.7 \%$ completeness, $0.32 \%$ contamination, and no strain heterogeneity. De novo assembly of SILVA database mapped reads resulted in two 16S rRNA gene contigs. Contig 1 (842 bp) showed $100 \%$ nucleotide sequence identity (e-value 0.00 , bitscore 1350 ) with the $16 \mathrm{~S}$ rRNA gene of Methylosinus sporium strain NCIMB 11126 as ordered from the DSMZ culture collection.

Contig 2 (1431 bp) showed 98.5\% nucleotide sequence identity (e-value 0.00 , bitscore 2328 ) to the $16 \mathrm{~S}$ rRNA gene of Methylocystis rosea strain SV97.

\section{Discussion}

Here, we present a proof of concept for the co-cultivation of anaerobic methanogenic archaea and aerobic methanotrophic bacteria in an oxygen-limited bioreactor. Only few studies have previously investigated co-cultivation of methanogens and methanotrophs (Gerritse and Gottschal 1993; Shen et al. 1996; Miguez et al. 1999). These studies showed that cocultivation of methanogens and methanotrophs is possible, but they did not provide in-depth data on species interactions and system operation. With the present study, we provide a method to study interspecies interactions between methane cycle microorganisms under oxygen limitation. FISH micrographs showed a tight spatial organization between the methanogenic sarcina clusters and layers of aerobic methanotrophic cells. This confirmed our hypothesis that methanotrophs profited from the production of methane from acetate by the methanogens and were therefore closely associated with the methanogens (Fig. 5). Methanogens are most likely protected against oxygen by methanotrophs (Fig. 5).

Genome sequencing of the methanotrophic culture indicated presence of both a Methylosinus and a Methylocystis 
species. Both species are members of the alphaproteobacterial family Methylocystaceae and possess pmoA genes encoding the particulate methane monooxygenase that oxidizes methane at atmospheric levels (Dunfield et al. 1999; Kravchenko et al. 2010). M. sporium is a suitable candidate for the co-cultivation set-up due to its high substrate affinity (Murrell et al. 2000). In addition, for $M$. trichosporium, that is closely related to M. sporium, $K_{m}$ values for methane were as low as $0.8-2.0 \mu \mathrm{M}$ depending on the strain (Joergensen and Degn 1983). Furthermore, M. sporium has often been used in previous methanogenic-methanotrophic cultures (Shen et al. 1996; Miguez et al. 1999). Acetate measurements (Fig. 4) showed acetate consumption by the methanotrophic culture. Genome data confirmed the presence of genes encoding acetate kinase (AckA), acetate-CoA ligase (ACSS), and phosphate acetyltransferase (Pta) in both genome bins. It is known that methanotrophs can metabolize acetate, but to our knowledge, growth on acetate and other carbon-carbon bond substrates had been thought to be limited to Methylocella and Methylocapsa species (Dedysh et al. 2005; Dunfield et al. 2010). The carbon fixation pathways showed the alphaproteobacterial type II pathway of formaldehyde conversion to L-Serine via 5,10-methylenetetrahydromethanopterin (5,10-methylene THMPT).

Co-culture studies could significantly contribute to our current knowledge on methanogen-methanotroph interactions in the environment. The metabolic processes that drive ecosystem-scale GHG fluxes are dependent on the activity of both the aerobic and anaerobic microbial community members (McCalley et al. 2014). Especially the interplay between methanogens and aerobic methanotrophs is relevant, since this determines the types and quantities of GHG fluxes into the atmosphere. The use of predefined methanogen-methanotroph co-cultures enables the study of environmental effectors including temperature, $\mathrm{pH}$, substrate, and oxygen availability on methane fluxes and methanogen-methanotroph interactions under controlled conditions. These studies could provide experimental evidence to better estimate wetland GHG fluxes. Methanogen-methanotroph interactions in the environment have recently gained more attention with the contradictory observations of oxic water column methanogenesis and methanogenesis in oxic soils (Bogard et al. 2014; Angle et al. 2017), aerobic methanotrophic activity in anoxic lake waters and sediments (Oswald et al. 2016; Martinez-Cruz et al. 2017), and fermentative activity of gammaproteobacterial methanotrophs under oxygen limitation (Kits et al. 2015). Our study provides a new method to study interspecies interactions of methane cycle microorganisms under an array of environmental conditions.
Acknowledgements MitZ, RR, TvdB, MAHJvK, and CUW designed, and MitZ, RR, TvdB, and MAHJvK performed the experiments. MitZ and RR analyzed the data. MitZ, MSMJ, and CUW wrote the article. We thank Guylaine Nuijten for the technical assistance with bioreactor set-up and operation and Rob de Graaf for practical help with the acetate determination protocol. We thank Jeroen Frank for technical assistance with genomic data assembly and binning. MitZ, CUW, and MSMJ were supported by the Nederlandse Organisatie voor Wetenschappelijk Onderzoek through the Soehngen Institute of Anaerobic Microbiology Gravitation Grant 024.002.002 and the Netherlands Earth System Science Center Gravitation Grant 024.002.001. MAHJvK was supported by the Technology Foundation Stichting voor Technische Wetenschappen Grant 13146. MSMJ was supported by the European Research Council Advanced Grant Ecology of Anaerobic Methane Oxidizing Microbes 339880. The funding agencies had no role in study design, data collection and interpretation, or the decision to submit the work for publication.

\section{Compliance with ethical standards}

Conflict of interest The authors declare that they have no conflict of interest.

Ethical statement This article does not contain any studies with human participants or animals performed by any of the authors.

Open Access This article is distributed under the terms of the Creative Commons Attribution 4.0 International License (http:// creativecommons.org/licenses/by/4.0/), which permits unrestricted use, distribution, and reproduction in any medium, provided you give appropriate credit to the original author(s) and the source, provide a link to the Creative Commons license, and indicate if changes were made.

\section{References}

Alneberg J, Bjarnason BS, De Bruijn I, Schirmer M, Quick J, Ijaz UZ, Lahti L, Loman NJ, Andersson AF, Quince C (2014) Binning metagenomic contigs by coverage and composition. Nat Methods 11:1144-1146. https://doi.org/10.1038/nmeth.3103

Amann RI, Binder BJ, Olson RJ, Chisholm SW, Devereux R, Stahl DA (1990) Combination of 16S rRNA-targeted oligonucleotide probes with flow cytometry for analyzing mixed microbial populations. Appl Environ Microbiol 56:1919-1925

Angle JC, Morin TH, Solden LM, Narrowe AB, Smith GJ, Borton MA, Rey-sanchez C, Daly RA, Mirfenderesgi G, Hoyt DW, Riley WJ, Miller CS, Bohrer G, Wrighton KC (2017) Methanogenesis in oxygenated soils is a substantial fraction of wetland methane emissions. Nat Commun 8:1-9. https://doi.org/ 10.1038/s41467-017-01753-4

Barbier BA, Dziduch I, Liebner S, Ganzert L, Lantuit H, Pollard W, Wagner D (2012) Methane-cycling communities in a permafrostaffected soil on Herschel Island, Western Canadian Arctic: active layer profiling of $m c r A$ and $p m o A$ genes. FEMS Microbiol Ecol 82: 287-302. https://doi.org/10.1111/j.1574-6941.2012.01332.x

Bogard MJ, Giorgio PA, Boutet L, Carolina M, Chaves G, Prairie YT, Merante A, Derry AM (2014) Oxic water column methanogenesis as a major component of aquatic $\mathrm{CH}_{4}$ fluxes. Nat Commun 5:1-9. https://doi.org/10.1038/ncomms6350

Bridgham SD, Cadillo-Quiroz H, Keller JK, Zhuang Q (2013) Methane emissions from wetlands: biogeochemical, microbial, and modeling perspectives from local to global scales. Glob Chang Biol 19:13251346. https://doi.org/10.1111/gcb.12131 
Brioukhanov A, Netrusov A, Sordel M, Thauer RK, Shima S (2000) Protection of Methanosarcina barkeri against oxidative stress: identification and characterization of an iron superoxide dismutase. Arch Microbiol 174:213-216. https://doi.org/10.1007/s002030000180

Bushnell B (2014) BBMap: a fast, accurate, splice-aware aligner. https:// jgi.doe.gov/wp-content/uploads/2013/11/BB_User-Meeting-2014poster-FINAL.pdf. Accessed 12 Feb 2018

Daims H, Bruhl A, Amann R, Schleifer K-H, Wagner M (1999) The domain-specific probe EUB338 is insufficient for the detection of all bacteria: development and evaluation of a more comprehensive probe set. Syst Appl Microbiol 444:434-444. https://doi.org/10. 1016/S0723-2020(99)80053-8

Daniels L (1993) Biochemistry of methanogenesis. In: Kates M, Kushner DJ, Matheson A (eds) The biochemistry of archaea (Archaebacteria), 1st edn. Elsevier Science, Amsterdam, p 61

Dedysh SN, Knief C, Dunfield PF (2005) Methylocella species are facultatively methanotrophic. J Bacteriol 187:4665-4670. https://doi. org/10.1128/JB.187.13.4665

Dunfield PF, Belova SE, Vorob'ev AV, Cornish SL, Dedysh SN (2010) Methylocapsa aurea sp. nov., a facultative methanotroph possessing a particulate methane monooxygenase, and emended description of the genus Methylocapsa. Int J Syst Evol Microbiol 60:2659-2664. https://doi.org/10.1099/ijs.0.020149-0

Dunfield PF, Liesack W, Henckel T, Knowles R, Conrad R (1999) Highaffinity methane oxidation by a soil enrichment culture containing a type II methanotroph. Appl Environ Microbiol 65:1009-1014

Ettwig KF, Butler MK, Le Paslier D, Pelletier E, Mangenot S, Kuypers MMM, Schreiber F, Dutilh BE, Zedelius J, De Beer D, Gloerich J, Wessels HJCT, Van Alen T, Luesken F, Wu ML, van de Pas-Schoonen KT, Op Den Camp HJM, JanssenMegens EM, Francoijs K-J, Stunnenberg H, Weissenbach J, Jetten MSM, Strous M (2010) Nitrite-driven anaerobic methane oxidation by oxygenic bacteria. Nature 464:543-548. https:// doi.org/10.1038/nature 08883

Frenzel P, Thebrath B, Conrad R (1990) Oxidation of methane in the oxic surface layer of a deep lake sediment (lake Constance). FEMS Microbiol Ecol 73:149-158. https://doi.org/10.1016/03781097(90)90661-9

Gerritse J, Gottschal JC (1993) Two-membered mixed cultures of methanogenic and aerobic bacteria in $\mathrm{O}_{2}$-limited chemostats. J Gen Microbiol 139:1853-1860. https://doi.org/10.1099/00221287-1398-1853

Graham ED, Heidelberg JF, Tully BJ (2017) BinSanity: unsupervised clustering of environmental microbial assemblies using coverage and affinity propagation. PeerJ 5:1-19. https://doi.org/10.7717/ peerj. 3035

Gupta V, Smemo K, Yavitt J, Fowle D, Branfireun B, Basiliko N (2013) Stable isotopes reveal widespread anaerobic methane oxidation across latitude and peatland type. Environ Sci Technol 47:82738279. https://doi.org/10.1021/es400484t

Hanson R, Hanson T (1996) Methanotrophic bacteria. Microbiol Rev 60: 439-471

Haroon MF, Hu S, Shi Y, Imelfort M, Keller J, Hugenholtz P, Yuan Z (2013) Anaerobic oxidation of methane coupled to nitrate reduction in a novel archaeal lineage. Nature 500:567-570. https://doi.org/10. 1038/nature12375

Joergensen L, Degn H (1983) Mass spectrometric measurements of methane and oxygen utilization by methanotrophic bacteria. FEMS Microbiol Lett 20:331-335. https://doi.org/10.1111/j.1574-6968. 1983.tb00142.x

Kage S, Kudo K, Ikeda H, Ikeda N (2004) Simultaneous determination of formate and acetate in whole blood and urine from humans using gas chromatography - mass spectrometry. J Chromatogr B 805:113117. https://doi.org/10.1016/j.jchromb.2004.02.029
Kang DD, Froula J, Egan R, Wang Z (2015) MetaBAT, an efficient tool for accurately reconstructing single genomes from complex microbial communities. PeerJ 3:1-15. https://doi.org/10.7717/peerj.1165

Kao-Kniffin J, Woodcroft BJ, Carver SM, Bockheim JG, Handelsman J, Tyson GW (2015) Archaeal and bacterial communities across a chronosequence of drained lake basins in Arctic Alaska. Nat Sci Reports 5:1-12. https://doi.org/10.1038/srep18165

Kiener A, Leisinger T (1983) Oxygen sensitivity of methanogenic bacteria. Syst Appl Microbiol 4:305-312. https://doi.org/10.1016/S07232020(83)80017-4

Kits KD, Klotz MG, Stein LY (2015) Methane oxidation coupled to nitrate reduction under hypoxia by the Gammaproteobacterium Methylomonas denitrificans, sp. nov. type strain FJG1. Environ Microbiol 17:3219-3232. https://doi.org/10.1111/1462-2920.12772

Knoblauch C, Beer C, Sosnin A, Wagner D (2013) Predicting long-term carbon mineralization and trace gas production from thawing permafrost of Northeast Siberia. Glob Chang Biol 19:1160-1172. https://doi.org/10.1111/gcb.12116

Kravchenko IK, Kizilova AK, Bykova SA, Men'ko EV, Gal'chenko VF (2010) Molecular analysis of high affinity methane oxidizing enrichment cultures isolated from a forest biocenosis and agrocenoses. Microbiology 79:114-122. https://doi.org/10.1134/ S0026261710010145

Li H, Durbin R (2018) Fast and accurate long-read alignment with Burrows-Wheeler transform. Bioinformatics 26:589-595. https:// doi.org/10.1093/bioinformatics/btp698

Li H, Handsaker B, Wysoker A, Fennell T, Ruan J, Homer N, Marth G, Abecasis G, Durbin R (2018) The sequence alignment/map format and SAMtools. Bioinformatics 25:2078-2079. https://doi.org/10. 1093/bioinformatics/btp352

Lu YY, Chen T, Fuhrman JA, Sun F (2018) COCACOLA: binning metagenomic contigs using sequence COmposition, read CoverAge, CO-alignment and paired-end read LinkAge. Bioinformatics 33:791-798. https://doi.org/10.1093/ bioinformatics/btw290

Mackelprang R, Waldrop MP, DeAngelis KM, David MM, Chavarria KL, Blazewicz SJ, Rubin EM, Jansson JK (2011) Metagenomic analysis of a permafrost microbial community reveals a rapid response to thaw. Nature 480:368-371. https://doi.org/10.1038/ nature 10576

Maeder DL, Anderson I, Brettin TS, Bruce DC, Gilna P, Han CS, Lapidus A, Metcalf WW, Saunders E, Tapia R, Sowers KR (2006) The Methanosarcina barkeri genome: comparative analysis with Methanosarcina acetivorans and Methanosarcina mazei reveals extensive rearrangement within methanosarcinal genomes. J Bacteriol 188:7922-7931. https://doi.org/10.1128/JB.00810-06

Maestrojuan GM, Boone DR (1991) Characterization of Methanosarcina barkeri MST Methanosarcina mazei S-6T, and Methanosarcina vacuolata Z-761T. Int J Syst Bacteriol 41:267-274. https://doi.org/ 10.1099/00207713-41-2-267

Martinez-Cruz K, Leewis M-C, Herriott IC, Sepulveda-Jauregui A, Anthony KW, Thalasso F, Leigh BM (2017) Anaerobic oxidation of methane by aerobic methanotrophs in sub-Arctic lake sediments. Sci Total Environ 607-608:23-31. https://doi.org/10.1016/j. scitotenv.2017.06.187

McCalley CK, Woodcroft BJ, Hodgkins SB, Wehr RA, Kim E-H, Mondav R, Crill PM, Chanton JP, Rich VI, Tyson GW, Saleska SR (2014) Methane dynamics regulated by microbial community response to permafrost thaw. Nature 514:478-481. https://doi.org/ 10.1038/nature 13798

Miguez CB, Shen CF, Bourque D, Guiot SR, Groleau D (1999) Monitoring methanotrophic bacteria in hybrid anaerobic-aerobic reactors with PCR and a catabolic gene probe. Appl Environ Microbiol 65:381-388

Moriya Y, Itoh M, Okuda S, Yoshizawa AC, Kanehisa M (2007) KAAS: an automatic genome annotation and pathway reconstruction server. 
Nucleic Acids Res 35:182-185. https://doi.org/10.1093/nar/ gkm321

Murrell JC, Mcdonald IR, Gilbert B (2000) Regulation of expression of methane monooxygenases by copper ions. Trends Microbiol 8:221225. https://doi.org/10.1016/s0966-842x(00)01739-x

Myhre G, Shindell D, Bréon F-M, Collins W, Fuglestvedt J, Huang J, Koch D, Lamarque J-F, Lee D, Mendoza B, Nakajima T, Robock A, Stephens G, Takemura T, Zhan H (2013) Anthropogenic and natural radiative forcing. In: Stocker T, Qin D, Plattner G-K, Tignor M, Allen S, Boschung J, Nauels A, Xia Y, Bex V, Midgley P (eds) Climate change 2013: the physical science basis. Contribution of working group I to the fifth assessment report of the intergovernmental panel on climate change. Cambridge University press, Cambridge, pp 659-740

Nurk S, Meleshko D, Korobeynikov A, Pevzner PA (2017) metaSPAdes: a new versatile metagenomic assembler. Genome Res 27:824-834. https://doi.org/10.1101/gr.213959.116.4

Oswald K, Milucka J, Brand A, Hach P, Littmann S, Wehrli B, Kuypers MMM, Schubert CJ (2016) Aerobic gammaproteobacterial methanotrophs mitigate methane emissions from oxic and anoxic lake waters. Limnol Oceanogr 61:101-118. https://doi.org/10. 1002/lno.10312

Parks DH, Imelfort M, Skennerton CT, Hugenholtz P, Tyson GW (2015) CheckM: assessing the quality of microbial genomes recovered from isolates, single cells, and metagenomes. Genome Res 25: 1043-1055. https://doi.org/10.1101/gr.186072.114

Prather MJ, Holmes CD, Hsu J (2012) Reactive greenhouse gas scenarios: systematic exploration of uncertainties and the role of atmospheric chemistry. Geophys Res Lett 39:6-10. https://doi.org/10. 1029/2012GL051440

Pruitt KD, Tatusova T, Maglott DR (2018) NCBI reference sequence (RefSeq): a curated non-redundant sequence database of genomes, transcripts and proteins. Nucleic Acids Res 33:501-504. https://doi. org/10.1093/nar/gki025

Raghoebarsing AA, Pol A, van de Pas-Schoonen KT, Smolders AJP, Ettwig KF, Rijpstra WIC, Schouten S, Damste JSS, Op den Camp HJM, Jetten MSM, Strous M (2006) A microbial consortium couples anaerobic methane oxidation to denitrification. Nature 440:10 13. https://doi.org/10.1038/nature04617

Raskin L, Stromley JM, Rittmann BE, Stahll DA (1994) Group-specific 16S rRNA hybridization probes to describe natural communities of methanogens. Appl Environ Microbiol 60:1232-1240

Roslev P, King GM (1994) Survival and recovery of methanotrophic bacteria starved under oxic and anoxic conditions. Appl Environ Microbiol 60:2602-2608

Rutherford K, Parkhill J, Crook J, Horsnell T, Rice P, Rajandream M-A, Barrell B (2000) Artemis: sequence visualization and annotation. Bioinformatics 16:944-945. https://doi.org/10.1093/ bioinformatics/16.10.944
Saunois M, Bousquet P, Poulter B, Peregon A, Ciais P, Canadell JG, Dlugokencky EJ, Etiope G, Bastviken D (2016) The global methane budget 2000-2012. J Earth Syst Sci 8:697-751. https://doi.org/10. 5194/essd-8-697-2016

Seemann T (2014) Prokka: rapid prokaryotic genome annotation. Bioinformatics 30:2068-2069. https://doi.org/10.1093/ bioinformatics/btu153

Shen C, Miguez C, Bourque D (1996) Methanotroph and methanogen coupling in granular biofilm under O2-limited conditions. Biotechnol Lett 18:495-500. https://doi.org/10. 1007/bf00140190

Sieber CMK, Probst AJ, Sharrar A, Thomas BC, Hess M, Tringe SG, Banfield JF (2017) Recovery of genomes from metagenomes via a dereplication, aggregation, and scoring strategy. bioRxiv. https://doi. org $/ 10.1101 / 107789$

Sliekers AO, Derwort N, Gomez JLC, Strous M, Kuenen JG, Jetten MSM (2002) Completely autotrophic nitrogen removal over nitrite in one single reactor. Water Res 36:2475-2482. https://doi.org/10.1016/ S0043-1354(01)00476-6

Smemo KA, Yavitt JB (2011) Anaerobic oxidation of methane: an underappreciated aspect of methane cycling in peatland ecosystems? Biogeosciences 8:779-793. https://doi.org/10.5194/bg-8-779-2011

Stahl DA, Amann RI (1991) Development and application of nucleic acid probes in bacterial systematics. In: Stackebrandt E, Goodfellow M (eds) Nucleic acid techniques in bacterial systematics. John Wiley \& Sons Ltd., Chichester, pp 205-248

Wu Y-W, Simmons BA, Singer SW (2015) MaxBin 2.0: an automated binning algorithm to recover genomes from multiple metagenomic datasets. Bioinformatics 32:605-607. https://doi.org/10.1093/ bioinformatics/btv638

Yang J, Jiang H, Wu G, Hou W, Sun Y, Lai Z (2012) Co-occurrence of nitrite-dependent anaerobic methane oxidizing and anaerobic ammonia oxidizing bacteria in two Qinghai-Tibetan saline lakes. Front Earth Sci 6:383-391. https://doi.org/10.1007/s11707-0120336-9

Yavitt J, Lang G, Downey D (1988) Potential methane production and methane oxidation rates in peatland ecosystems of the Appalachian Mountains, United States. Glob Biochem Cycles 2:253-268. https:// doi.org/10.1029/GB002i003p00253

Yoon S-H (2016) Principle of membrane filtration. In: Membrane bioreactor processes principles and applications. Taylor \& Francis Group, Boca Raton, pp 1-49

in 't Zandt MH, Beckmann S, Rijkers R, Jetten MSM, Manefield M, Welte CU (2017) Nutrient and acetate amendment leads to acetoclastic methane production and microbial community change in a non-producing Australian coal well. Microb Biotechnol 0:1-13. https://doi.org/10.1111/1751-7915.12853

Zhou J, Bruns MA, Tiedje JM (1996) DNA recovery from soils of diverse composition. Appl Environ Microbiol 62:316-322 